Educational Management,

Administration and Leadership

\title{
Principals' metaphors as a lens to understand how they perceive leadership
}

\begin{tabular}{|c|l|}
\hline Journal: & Educational Management Administration \& Leadership \\
\hline Manuscript ID & EMAL-2016-181.R4 \\
\hline Manuscript Type: & Original Article \\
\hline Keyword: & $\begin{array}{l}\text { Educational leadership, Leadership models, Leadership metaphors, } \\
\text { Metaphorical thinking, Conceptions of leadership, Leadership motivation }\end{array}$ \\
\hline Abstract: & $\begin{array}{l}\text { A prolific number of researchers have chosen to study metaphorical } \\
\text { narratives, confirming their usefulness in educational research. The aim of } \\
\text { this paper is to analyse the metaphorical expressions used by } 68 \text { principals } \\
\text { from infant, primary and secondary schools in Alicante (Spain), concerning } \\
\text { the way they see the figure of the principal and how it makes them feel. } \\
\text { The data were processed using AQUAD 7. Results indicated a weak } \\
\text { presence of characteristics related to social and contextual leader learning, } \\
\text { as principals' views tended more towards traditional models with duty } \\
\text { predominating as a motivating force. Such views are usually associated } \\
\text { with the experience of negative emotions. Findings highlighted the need to } \\
\text { introduce an important cognitive and dispositional change in leadership } \\
\text { education to ensure the development of professional skills aligned with } \\
\text { current shared leadership models. }\end{array}$ \\
\hline
\end{tabular}

\section{SCHOLARONEm \\ Manuscripts}




\title{
Principals' metaphors as a lens to understand how they perceive
}

\section{leadership}

\begin{abstract}
A prolific number of researchers have chosen to study metaphorical narratives, confirming their usefulness in educational research. The aim of this paper is to analyse the metaphorical expressions used by 68 principals from infant, primary and secondary schools in Alicante (Spain), concerning the way they see the figure of the principal and how it makes them feel. The data were processed using AQUAD 7. Results indicated a weak presence of characteristics related to social and contextual leader learning, as principals' views tended more towards traditional models with duty predominating as a motivating force. Such views are usually associated with the experience of negative emotions. Findings highlighted the need to introduce an important cognitive and dispositional change in leadership education to ensure the development of professional skills aligned with current shared leadership models.
\end{abstract}

Keywords: Educational leadership; Leadership models; Leadership metaphors; Metaphorical thinking; Leadership motivation; Conceptions of leadership.

\section{Introduction}

The complexity surrounding the term leadership makes it no less attractive, as it is generally recognised as the driving force behind improvements in education. Numerous studies have 
highlighted the close relationship between principal's leadership practices, the quality of teaching and student results (Bruggencate et al., 2012; Gu and Johansson, 2013).

This research focuses on the conceptions that principals have of their position as a catalyst for their action. We consider metaphors to be objects of research. They are not just figures of speech but an essential mental mechanism (Avidov, 2016). Metaphors have not only linguistic but also psychological consequences, since their symbolism stems from the way the physical and social environment is conceived, perceived and felt (Lee and Schwartz, 2012).

\subsection{Metaphors as tools in educational research}

We are born to learn continuously throughout our lives. Most of our learning is informal. We learn through experience and inquiry, from others and with others. Our learning environment shapes us and our learning is shaped both mentally and through our actions. In this process we tend to turn our experiences into metaphorical stories that give meaning and expression to our life, our emotions and our feelings. Metaphors also help to structure and conceptualise our cognition through the interplay between experience, context and mind. They are useful not only in preserving the footprint of our past, but also in helping us to act in the present (Saban, 2010).

Morgan (1986) stressed the value of the metaphor as a tool to aid the actions of an organisation based on the image it has of itself. Thus principals' actions can vary considerably depending on the image they have of themselves as leaders, and this will be a combination of their conceptions (ideas and beliefs about principalship, resulting from reflection), perceptions (processes related to their position, whereby the information received via the senses is identified, organised and interpreted) 
and feelings (emotional states or reactions involving situations or things connected to principalship). Therefore a principal who sees and feels the job as an adventure will deal proactively with the different situations that arise, whereas one who sees it as a nightmare will deal with them with frustration. Some of the participants in Argyropolou and Hatira's (2014) study chose to represent the duality of the principals' role using metaphors of beasts of burden (e.g. horses) or many-armed figures. Alvesson and Spicer (2010) present six metaphors for leaders (saint, gardener, buddy, commander, cyborg and bully), which again show their potential for justifying how they act based on how they see themselves.

Since Lakoff and Johnson's (1980) seminal work, many researchers including Barsalou (1999) and Slepian and Ambady (2014) have chosen metaphorical narratives as an object of study. They have not only considered the powerful linguistic use of the metaphor, whereby two different ideas (the source and the target) connect to form a comparison that brings clarity and makes a reality comprehensible; they have also explored its potential as a cognitive tool that could even determine the action. Discussions on these theories revolve around the unidirectionality and bidirectionality of the sensorimotor-conceptual relationship in the use of metaphors. One argument is that the experiences and feelings generated by leadership will unidirectionally condition how it is conceptualised and what metaphor will be used to describe it. Another seeks to explain the bidirectionality in this metaphor-processing sensorimotor-conceptual relationship on the basis of previous experience alone. Sensorimotor experience in the area of leadership will therefore condition conceptualisation, and this in turn will condition subsequent actions and experience. 
Meanwhile a different line of thought goes one step further by understanding that the learning of metaphors for leadership, in this case with no previous sensorimotor experience, could condition the way it is conceptualised and any actions deriving from it. This means that metaphors become an instrument for professional learning and should be included as part of the principals' training programs.

However, it is not our intention in this study to advocate a theory on the relationship between metaphors and cognition but to recognise its value as a tool capable of making explicit the tacit, implicit knowledge resulting from the conceptions, perceptions and feelings experienced (Patchen and Crawford, 2011). Metaphors are the bridge that links theory and practice, language and movement, conceptualisation and action, aiding understanding of the social contexts in which we participate, which in turn influence the way they are used and understood, given that we observe and mentally process our environment through a cultural lens (Saban, Kocbeker \& Saban, 2007). Thus the tool provides descriptions and meanings that reflect the culture and contexts in which we participate (Akar and Yildirim, 2011).

Identifying the metaphors used by agents in the field of education enables us to ponder a number of variables, such as how they perceive their role, the purpose of their actions, their educational and teaching models, etc. Mahlios, et al. (2010), Pinnegar et al. (2011) and Thomas and Beauchamp (2011), for instance, consistently emphasised that one way to examine students' beliefs in preservice teacher education is to identify the conceptual tools they use to make sense of their life, with the analysis of metaphors being a powerful resource. Along similar lines, several authors such as 
Zhao et al. (2010) have highlighted how the conceptions and beliefs of these students will mark certain behaviour in their future professional practice.

Hence we firmly believe that principals' academic and professional background in schools influences both their conceptions and beliefs, which leads us to consider that their metaphors do not result only from their professional experience as principals but also from their previous thoughts and feelings on the subject and from their school culture and context. Questioning and analysing their leadership metaphors could be a way of activating a new cognitive and dispositional background for the development of professional skills through discourse and debate.

\subsection{Ways of understanding leadership}

The concept of leadership could be compared to a polyhedron, which can be understood from multiple perspectives. Despite the complexity, three common dimensions noted by Bush (2011) can be identified: influence, values and vision. Leadership involves engaging in a social and cultural influential process that has an impact on the activities and relationships established in a community or organisation. This process directs participants towards action and goals. Thus the central concept is influence and not authority; process and not product; and ultimately vision and values.

An in-depth review of a range of perspectives enabled us to follow the concept's development through several stages. The perspectives considered were: who exercises leadership, how goals are defined and the way principals move towards achievement (Bass and Bass, 2008). A number of models or patterns can be identified in these perspectives, which reflect and inform changes in school leadership practices (Bush and Glover, 2014). Indeed, following an analysis of several model 
classifications (Bush, 2011; Bush and Glover, 2014; Davis et al., 2005), a shift was observed from individual, heroic and authority models to shared, collegial and distributed ones.

With individual leadership the institutional vision resides in the leader, who normally adopts an authoritarian, personalist stance. Shared leadership, however, is characterised by the fact that the institutional vision is not an individual but a common preserve. Leadership is delegated, social relations are strong and trust is high (Crawford, 2012). Thus the way other members influence and contribute to transforming and improving the community is acknowledged.

Table 1 shows the different leadership models described by Bush and Glover (2014). This amalgamation is based on either individual or shared perspectives.

Table 1. Classification of leadership models

\begin{tabular}{|c|c|}
\hline Individual models of leadership & Shared models of leadership \\
\hline Managerial leadership & Distributed leadership \\
\hline Instructional leadership & Leadership for learning \\
\hline Transformational leadership & Teacher leadership \\
\hline Moral and authentic leadership & System leadership \\
\hline
\end{tabular}

As seen in Table 1, the first column contains those models with a single formal source of power. The differences between them lie in the different kinds of objectives and the way principals seek to achieve them. In managerial leadership, for example, the source of leadership focuses on administrative functions allowing the proper development of other areas in the school (Bush and Glover, 2014). Instructional leadership concentrates on teaching processes and the way principals 
and teachers can foster student outcomes (Robinson et al., 2008). Unlike these two examples, transformational leadership is based on leaders' capacities to make other members of the organisation exceed their expectations, the objective therefore being centred on cultural change (Bass and Riggio, 2006). Moral and authentic models highlight how leadership actions are determined by the value systems held by principals (Starratt, 2004).

The opposing column emphasises different ways of exercising leadership based on collegiality, collaboration and shared vision. The key source here is not the individual but the community. Leadership is not based on formal power or hierarchy but on the conjunction of formal and informal sources seeking expertise in the community. Distributed leadership, for instance, is based on the distribution of power in the school, regardless of formal position or role (Harris, 2013; Liljengerg, 2015). Leadership for learning, on the other hand, has evolved from the instructional model. In this case power originates not only from the principal but also from the community, focusing more on learning than on teaching processes (Bush and Glover, 2014). Meanwhile, teacher leadership highlights the empowerment of teachers to ensure school development (Frost, 2008). Finally, system leadership promotes the existence of a school network that shares leadership, and in which success comes not only from one school but from a group of schools (Hopkins and Highman, 2007). According to Alvesson and Spicer (2010), metaphors provide a way of understanding leadership and the ambiguity associated with it. The way principals see leadership could determine the metaphors behind the practice, with the practice leading to a reconceptualisation of the metaphors. Analysing them could allow us to recognise the character of the principals' leadership models 
(individual vs. social) according to who exercises leadership, how goals are defined and the way principals move towards achievement.

\subsection{Leadership perspectives and their impact on schools}

Since the 1970s and 1980s, a large number of publications have shown the value of leadership for learning improvement. These have considered principal leadership as the factor with the second greatest impact on learning (Gu and Johanson, 2013; May and Supovitz, 2011). In fact there is general agreement that the effect of leaders on student outcomes is indirect, whereas leaders have a direct influence on what teachers want to do, what they believe in and how they can improve their practices and the community as a whole (Day et al., 2009; Robinson et al., 2009).

Principals have an impact on learning results through teachers (Robinson et al., 2008). Consequently, effective leaders usually develop a series of practices that promote professional teacher development and their leadership role. This professional growth improves teachers' performance in classrooms and learning outcomes. Hence, it is important to emphasise that leaders' visions and actions create and cultivate learning communities where teachers share leadership, practices, responsibilities and prospects (Katzenmeyer and Moller, 2009).

Thus teachers' professional development and students' learning outcomes also depend on context (Day et al., 2011), which means that the leaders' practices might be adapted to each scenario. Since principals are the key for modelling the school environment, they need to strive to develop a school culture that encourages student learning and teacher development. 


\begin{abstract}
It seems that not every leadership model, i.e. the style or set of styles characterising a principal's
\end{abstract} actions, has the same impact or repercussion on school culture and practices (Day et al., 2016). An authoritarian model of leadership, for example, generates a restricted, static school culture very different from the dynamic, collaborative culture generated by a distributed leadership model. Educational literature has focused mainly on instructional, transformational and distributed leadership. Experts have noted that results are better when leaders are involved in curriculum planning and professional development, are interested in cultural change and are able to distribute responsibility and decisions among the educational community. Bush and Glover's (2014) proposal of a contingent model is very valuable when the perspectives are so blurred. A single model provides helpful but partial insight, and therefore they suggest adapting the model to each particular situation and context.

The merging of socially, politically and economically complex aspects requires school leadership to come from the shared work of leaders and educational community participants. Transforming schools is possible with a set of actions that allows community participants to share and engage in professional development. We firmly believe that attention to a situational model is necessary, but it should focus especially on shared models (Harris, 2013; Lambert et al., 2002).

Although more research is necessary for causal relationships to be established with confidence, shared leadership models lead schools to efficacy and success, affecting the attractiveness of the role. More empirical research is also needed to prove the correlation between the role adopted in 
schools and how comfortable leaders feel in their role, as leadership is becoming an ever more complex task generating pressure on those who undertake it (Tucker, 2010).

\subsection{Metaphors and leadership models: research questions}

Metaphors, as a research instrument, form part of educational literature and have made a significant contribution to professional teacher learning (Seiler, 2013). They could therefore be a significant source of knowledge for leaders' professional learning too.

This study uses principals' metaphorical narratives as a source of inquiry into the views and perspectives underlying leadership. To this end, three research questions were formulated:

1) How do principals view leadership?

2) How do these principals feel about their role as leaders?

3) To what extent do they perceive that the way they do their job follows an individual or shared leadership model?

\section{Methodology}

The research falls within the framework of the paradigm of naturalist inquiry (Lincoln and Guba, 1985) insofar as it is adapted to the subject under study, being based on an analysis of the metaphors contributed by 68 principals regarding how they perceive their role and the feelings implicit in the models identified. It also identifies the character that this conception takes on, depending on how far they see their position as being shared. From this methodological approach and by way of an analysis of the content of their metaphors, the principals' conceptions, perceptions 
and feelings are analysed in their professional context, since studying them outside this scenario would be meaningless.

The research technique chosen was content analysis, defined as a method for classifying spoken or written information into categories with similar meanings (Cole, 1988). Unlike grounded theory (Glasser and Strauss, 1967), and despite the fact that the aim of the study was not just to generate new theory on leadership, the analysis process has not been closed. In this case the intention was to assess the participants' leadership models on the basis of a pre-defined theoretical framework. However, no theoretical benchmark has been used to analyse their type of motivation or the emotions associated with it and with their roles, which means that the information has emerged from the data. Therefore, bearing in mind Hsieh and Shannon's (2005) classification of content analysis approaches, we used direct content analysis (based on pre-defined theoretical ideas) to identify the leadership models, conventional analysis (open coding) to describe the motivations and the emotions associated with both dimensions (roles and motivations), and summative content analysis, whereby frequencies have been located to complement information of a narrative nature.

\subsection{Context}

Under current Spanish legislation, the General Act of Parliament 8/2013, of 9 December, for the Improvement of Quality in Education, ${ }^{1}$ the requirements necessary for becoming a principal include (1) having been a career civil servant in public education for at least five years, (2) having taught directly as a career civil servant for at least five years in one of the teaching areas applied for, (3)

\footnotetext{
${ }^{1}$ Hereafter LOMCE
} 
being accredited as having completed a training course given by the Ministry of Education and Culture or relevant Education Authority, and (4) presenting a principal's plan of action.

Principal selection is carried out via a process which includes participation by the education community and the Education Authority. Selection is made through competition, following principles of equality, advertising, merit and ability. Highly valued aspects include previous experience in a school management team, active service situation, current position and, where applicable, having gained a positive assessment in the development of quality action plans. The Education Authority appoints principals for a period of four years, renewable for further four-year periods (subject to positive assessment), although it can also set a limit on renewing mandates.

An analysis of the various laws governing the Spanish education system shows the changes to the profile and tasks performed by principals. The current law, LOMCE (2013), has given principals stronger decision-making powers to the detriment of the competencies of the School Council. The most prominent are management autonomy in developing quality actions and an increasing importance in exercising pedagogical leadership, with consequent innovation and improvement activities for schools. However, despite progress being made, some authors have stressed that the last Education Act disregarded the leadership guidelines proposed by the international literature and maintained a bureaucratic and managerial model (Bolívar and San Fabián, 2013). This could stem from the fact that, regardless of what state legislation says, in practice leadership in schools tends to be closely linked to an administrative vision. Principals in Spain have very little autonomy, as in 
other countries within the European framework such as France and Germany (Ärlestig et al., 2016; Hancock et al., 2012), and their work is greatly restricted by the Administration.

\subsection{Participants}

This study comprised 68 principals from infant, primary and secondary schools in Alicante (Spain). Of these, $35.3 \%$ were women and $64.7 \%$ men. The highest proportion of participants $(29.4 \%)$ were aged between 51 and 55 , followed by $22 \%$ between 56 and 60 , which shows the personal maturity of those surveyed.

$38.8 \%$ of participants had between 31 and 35 years' teaching experience, while $19.1 \%$ had between 26 and 30 years' experience. These figures show that many participants have a lengthy teaching trajectory. As regards the time spent as principal, most have been in the job between 0 and 12 years (75\%). In this case the highest proportion was of principals who, when the interviews were carried out, had been in the post for between 5 and 8 years (27.9\%), followed by $25 \%$ between 9 and 12 years.

As for where they work, $58.8 \%$ were principals in infant and primary schools and $41.2 \%$ in secondary schools. Generally speaking many of these schools (38.2\%) have between 401 and 600 pupils and, in many cases (45.7\%), between 26 and 50 teachers.

The candidate selection process was aided by three inspectors from the Alicante Education Inspectorate, who provided us with a list of contacts. The inspectors selected those candidates that they considered would be amenable to participating and whose opinions would be representative of 
principals in the cultural and social context of Alicante. The inspectors had a professional relationship with them, as they were part of their allocated districts. Of the 100 principals interviewed, 68 answered the question requesting that they suggest a metaphor representing the principal.

The inspectors sent these participants an e-mail informing them of the study's aims and that we would contact them direct.

\subsection{Data collection instrument}

Semi-structured interviews were used to collect data. Given that this study was part of a larger one on educational leadership, the final instrument — validated by three experts on educational research — contained nine closed items for collecting socio-demographic data and twelve open questions (Appendix A). These questions were designed to collect data on five subjects: i) willingness to take up the post; ii) professional identity of the principals; iii) professional development; iv) achievements and difficulties; and v) needs and proposals. The study emerged from the responses to the last interview question, where participants were asked to suggest a metaphor to represent the figure of the principal, associated with the second of the subject areas listed above.

All interviews were recorded with the consent of the participants. They were informed that participation in the study was voluntary and that their responses would remain anonymous. The participants suggested the day, time and place of the meeting. The interviews were carried out by a single interviewer. 
Most interviews took place in the principals' offices and lasted an average of approximately thirty minutes each. The data collection process took place over a four-month period.

\subsection{Data processing and analysis}

The use of qualitative methodology allowed researchers to analyse and interpret responses within that specific social context (Cho and Lee, 2014). The data collection comprised 96 metaphors described by 68 principals, as this narrative tool contained and expressed the richness and variety of participants' stories (Huber et al., 2013).

After the narratives were collected, iterative readings of the metaphors were carried out, allowing us to design a coding system to analyse them using the AQUAD 7 software tool (Huber and Gürtler, 2013). This Qualitative Data Analysis programme was chosen for its ability to facilitate the interpretation process, providing emerging categories from participants' narratives to address the research questions. The data analysis used a deductive-inductive process, which was useful in adapting the analytical tool to interpretation. The inductive process, related to motivations and feelings, included open coding, creating categories and abstraction (Elo and Kyngäs, 2008). The deductive process, related to individual and shared leadership, formed the categorisation matrix development, whereby the data were reviewed for content and coded for correspondence with Bush and Glover's (2014) theory.

The encoding instrument was analysed and validated by three researchers until a final configuration was reached. The first draft was also adjusted because the intensity and possible variants emerging 
from the narratives demanded a deeper understanding of the subject being studied. Narrative units were identified by an alphanumeric system to ensure participant anonymity.

In this recursive process between the participants' metaphors and the research questions, the coding system was continuously adapted. Five codes emerged as regards the principal's view of leadership. These codes were classified into two categories, given that their emotional weight enabled differentiation. While the metaphors in the first category can be related to a particular leadership model (directive, paternalistic and guiding) because they are formulated from a more technical and rational point of view, those in the second category are of a more visceral character and cannot be related to the models identified for the first; they express what motivates participants to lead. A desire to make a crossover study of the two views to identify the type of motivation associated with each leadership model led us to carry out another analysis.

The metaphors also showed whether the principal's view was associated with positive or negative emotions and whether it was experienced as something individual, concerning them alone, or clearly reflected the feeling that the principal worked within a social community (see Appendix B).

The individual role and social view codes were established following certain relevant indications for categorisation, because principals sometimes used the same metaphor with different meanings. For example, the principal as the first carriage of a train was a frequently-cited metaphor, but with different connotations. For some, the first carriage plays a full role in deciding the route, while for others it is just one more element of the whole. These explanations denote different visions, varying individual or social perspectives, which were useful in the coding process. 
An individual point of view means the principal thinks they have to do everything without considering any notion of sharing or delegating: "Go-to guy. A troubleshooter, that's what it really is (P_033)". From a social point of view, although principals are an important element they still recognise the relevance of the team and the community: "You're the front carriage of the train but the principal doesn't run the school. A team runs it $\left(\mathrm{P}_{-} 028\right)$ ". It is important to note that this perspective is not necessarily representative of a shared model of leadership. A principal may, for example, show concern for the education community (social interest) but exercise leadership from an individualist stance.

\section{Results}

This section shows the findings of a narrative character for the study's two categories, which are complemented by the descriptive data for the percentage of frequency. This is calculated using the formula Fx100/Total F. Thus Table 2 shows the number of times principals refer to a code as a proportion of all the frequencies as a whole.

It can be seen that the difference between the total frequencies of one category and the other is minimal (rational view 52\% and motivational view 48\%). As regards the individual or social perspective of the job, although the total frequencies indicate that the individual view has more weight, it should be pointed out that the social is predominant in the rational view $(\mathrm{F}(\%)=32.3)$ and the individual in the motivational view $(\mathrm{F}(\%)=42.7)$. 
Table 2. Frequency percentages of research codes

\begin{tabular}{llcccccc}
\hline Categories & Codes & $\begin{array}{c}\text { F (\%) } \\
\text { Individual }\end{array}$ & $\begin{array}{c}\text { F (\%) } \\
\text { Social }\end{array}$ & $\begin{array}{c}\text { F (\%) } \\
\text { Total }\end{array}$ & $\begin{array}{c}\text { F (\%) } \\
\text { Positive } \\
\text { feelings }\end{array}$ & $\begin{array}{c}\text { F (\%) } \\
\text { Negative } \\
\text { feelings }\end{array}$ & $\begin{array}{c}\text { F (\%) } \\
\text { Total }\end{array}$ \\
\hline & 1.1 Guiding model & 13.5 & 21.9 & 35.4 & 12.5 & 22.9 & 35.4 \\
1. Rational view & $\mathbf{1 . 2}$ Paternalistic model & 2.1 & 10.4 & 12.5 & 4.2 & 8.3 & 12.5 \\
& $\mathbf{1 . 3 ~ D i r e c t i v e ~ m o d e l ~}$ & 4.2 & 0 & 4.2 & 0 & 4.2 & 4.2 \\
\hline $\begin{array}{c}\text { 2. Motivational } \\
\text { view }\end{array}$ & $\mathbf{2 . 1}$ Duty motivation & 36.5 & 1 & 37.5 & 0 & 37.5 & 37.5 \\
\hline Total & $\mathbf{2 . 2}$ Hedonism motivation & 6.2 & 4.2 & 10.4 & 10.4 & 0 & 10.4 \\
\hline
\end{tabular}

As far as the principal's emotions are concerned, the results indicate that negative emotions predominate in both views.

\subsection{Category 1 Rational view}

The first category covers those metaphors referring to a leadership model identified in the education literature and therefore corresponds to a more rational and technical view. Although these contributions have less emotional weight than those in the second category, they do have emotional connotations. This association (leadership model and emotions) is presented at the end of the results section.

\section{Code 1.1 Guiding model}

Code 1.1 analyses those metaphors identified as being closer to the role of a guide. The principal is seen as counsellor, coordinator and facilitator. These are the metaphors that accumulated the highest percentage of frequencies $(\mathrm{F}(\%)=35.4)$ in the first category. Three shades of meaning can be distinguished, as shown in Table 3. The first of these includes metaphors that place the principal at the forefront, i.e. as the person who guides the group and opens up the way for everyone else, hence the frequent use of terms like bulldozer and road builder. This is the same sense given by metaphors 
equating the principal to a furrow or channel, a tourist guide or a train locomotive (examples 1a and $1 b)$.

The second shade of meaning covers the task of coordination (example 2a). Participants stress that they do not have one particular function, as would be the case with the conductor of an orchestra, who plays no particular instrument but has to be able to harmonise and coordinate the efforts and work of the musicians (example 2b).

Finally the third shade of meaning stresses the facilitating character that a school principal must have, but also places specific value on the work of others, i.e. it links the principal's successes to the success of community members, as in the case of sports coaches (example 3a). The principal is considered to be just another part of the system. It also acknowledges the pointlessness of a principal unsupported by everyone else's work, which brings to mind distributed leadership. References to cogs and assembly lines and Formula 1 drivers who need their team in order to finish the race are illustrations of this (example $3 b$ ).

Table 3. Examples of metaphors for code 1.1 Guiding model

\footnotetext{
1a/I You're like water. You move along bit by bit, finding your way, until finally the channel opens up and you pass through. (P_009)

1b/I You're a tourist guide marking out the route. ( $\left.\mathrm{P}_{-} 020\right)$

2a/I The principal's like an octopus. I've got a head and lots of arms and legs, but what I actually do is coordinate what everyone else does. (P_045)

2b/S The principal's like the conductor of an orchestra, who doesn't play an instrument. The orchestra can function by itself without the conductor because everyone knows how to play the trombone, the cymbals and the clarinet, but they need someone who in some way coordinates. (P_004)

3a/S I think the coach's fate depends on the successes and failures of the team. (P_037)

3b/S You're just another driver, but to make it go you have to have a good team to help you. (P_068)
} 
In the conception of the principal as a guide, the social perspective $(\mathrm{F}(\%)=21.9)$ prevailed over the individual $(\mathrm{F}(\%)=13.5)$. The principal's role is understood as being a guide with a social angle, involving leadership in a learning community where everyone participates and learning occurs within community practices (examples $2 b-3 b)$.

As regards the role of guide, from an individual perspective the spotlight falls on the principal who has the ability to guide, but also to take individual responsibility and make decisions that the members of the community must follow (examples 1a-2a).

\section{Code 1.2. Paternalistic model}

Table 4 shows that the participants' metaphorical stories reflect three different types of view: (1) metaphors related to a dream vision, (2) metaphors visualising principals as individual patriarchal figures who love and care for teachers and students from a heroic perspective, and (3) metaphors extolling the social capacity that the principal must have in order to keep all members of the community happy. The three types of metaphor reflect an idealised conception of the position.

\section{Table 4. Examples of metaphors for code 1.2 Paternalistic model}

\footnotetext{
1a/I We'd have to be dream sellers. (P_009)

1b/I The principal would have to be a smile. (P_024)

2a/S You're the head of the family. You know your children and grandchildren. You have a duty to promote their strengths and have a good relationship with them. (P_013)

2b/S I've often felt like a medieval knight in armour defending the school and everything inside it. (P_040)

$3 \mathrm{a} / \mathrm{S}$ I think that what it most resembles is the executive board of a company. And I'd add that it's one of those companies with a soul. The board of an NGO, for example. (P_008)

3b/S SpongeBob SquarePants embodying the quintessence of social skills, taken to extremes and aiming to
} 


\section{(1) Dream view; (2) Patriarchal view; (3) Servant view; (I) Individual perspective; (S) Social perspective} case of examples $1 \mathrm{a}$ and $1 \mathrm{~b}$. This idyllic vision is complemented by the heroic aspect of the metaphors in the second group, which allude to a paternal, accommodating style of leadership. The principal is referred to at all times as the defender of the various members of the community. There are frequent mentions of metaphors similar to example 2a, likening the principal's position to that of the head of the family or other family members who have a responsibility to serve, know and protect. These qualities are also represented by elements like the sun, which has the capacity to give heat, or the heroic nature of a medieval knight (example 2b). Ultimately they reveal the concern they feel that the work they do should please all the members of the community. This leads them to stress the personal touch they bring to the job and the need to develop social skills (examples $3 \mathrm{a}$ and $3 b)$.

Looking at the differences between metaphors depending on their individual or social nature, the individual paternalistic perspective (examples $1 \mathrm{a}-1 \mathrm{~b}$ ) is represented by a frequency of $2.1 \%$, and the social paternalistic perspective by a frequency of $10.4 \%$. This social view, which is predominant, is reflected in a group of narratives that show a kind of sweet patriarchal and servant view of the participants (examples 2a-3b). 


\section{Code 1.3 Directive model}

Code 1.3 includes metaphors that express the leadership function as being hierarchical, directive and individual. These give an impression of the principal as having sole responsibility, as seen in examples $1 \mathrm{a}$ and $1 \mathrm{~b}$ in Table 5. The metaphorical view magnifies the figure of the principal as the only source of decision-making. It also represents an individualised approach to leadership, where the hierarchical principal-teacher relationship is stressed.

\section{Table 5. Examples of metaphors for code 1.3 Directive model}

\footnotetext{
1a/I You're like a navel. You're at the centre of everything and everything's your responsibility. (P_055)

1b/I The principal is a ship's captain who has to make a decision at a certain moment in time. Stormy weather is coming, although it might not seem so, and the captain believes it necessary to change course. (P_042)
}

(1) Directive role; (I) Individual perspective

Metaphors that consider the principal as the main player and authority in the school community were not often found in the study $(\mathrm{F}(\%)=4.2)$. This low frequency percentage is probably due to the social and cultural rejection of an individual perspective where the central concept is the principal's power.

\subsection{Category 2. Motivational view}

The second category contains metaphors referring to the participants' motivation to lead when performing their role. These metaphors are formed viscerally, and classifying them sketches out two very different extremes: (1) motivation for the leadership function through feeling a certain responsibility and pressure to take on the duty it involves, and (2) motivation due to a perception of 
the job as an opportunity to grow and due to a sense of hedonism. Their character means that they cannot be included in the leadership models identified in the first category.

\section{Code 2.1 Duty motivation}

Code 2.1 includes metaphors that reflect that the motivation for the job stems from the pressure, difficulty and duty that the principals believe the position entails, as seen in Table 6 . From the contributions as a whole, three different shades of meaning can be distinguished: (1) work overload, (2) responsibility, and (3) negative feelings. As regards the first of these, we find a group of metaphors that reflect the idea that the principal can never stop working, hence the reference to Sisyphus and his boulder (example 1a), meaning that the principal's work is never-ending (example 1b). In this regard other metaphors, such as the Indian goddess with numerous arms and those alluding to the over-qualified caretaker or troubleshooter, reflect the huge number of matters that have to be dealt with and problems that have to be solved.

The second shade of meaning covers metaphors that highlight the great responsibility the job is assumed to carry. The shield and the front wall of a squash court are two examples that illustrate this $(2 \mathrm{a}$ and $2 \mathrm{~b})$.

Finally there is a considerable number of metaphors referring to the negative feelings instilled by the job, such as loneliness and frustration (examples $3 \mathrm{a}$ and $3 \mathrm{~b})$.

\section{Table 6. Examples of metaphors for code 2.1 Duty motivation}

1a/I It's like the boulder of Sisyphus. The guy pushes the boulder and when you get to the top of the mountain you let go of the boulder, it rolls back to the bottom, and then you go back down...It's 
1b/I It could be "The NeverEnding Story". (P_067)

2a/I They're a shield; they're what receives all the knocks. You complain, but anyone with any sort of position has to carry a lot of responsibility. ( $\left.\mathrm{P}_{-} 011\right)$

2b/I We're like a wall in a squash court in the sense that, even if the school's falling down, you have to give the impression that everything's fine. (P_062)

2c/S The metaphor would be flexibility because, in the end, it's adapting to the environment. Otherwise, there is no adaptation. ( $\mathrm{P}_{-}$038)

3a/I You're alone. Although I'm not really alone, it's the feeling of the long-distance runner. It doesn't matter what happens, because you're responsible for everything. (P_014)

3b/I It's crossed my mind that it's like chewing gum. At first you say it's great and then you don't like it as much when it turns bitter. (P_031)

(1) Work overload; (2) Responsibility; (3) Negative feelings; (I) Individual perspective; (S) Social perspective

As was shown in Table 2, the highest percentages of the study correspond to negative feelings such as frustration, anxiety, workload, etc. This sacrificial vision is more closely related to an individual perspective $(\mathrm{F}(\%)=36.5)$ than to a social one. According to Table 6, principals also argued that they have to be multi-faceted because of the lack of help (examples 1a and 3a). In contrast, only one example has been characterised of a metaphor that combines negative feelings with a social perspective $(2 \mathrm{c})$.

\section{Code 2.2 Hedonism motivation}

This code incorporates metaphors that associate the motivation to lead with personal fulfilment, satisfaction and positive experiences, as seen in Table 7. Unlike the previous code, here the principals have a pleasure motivation for the job, because it is through work that they experience high levels of satisfaction. Two shades of meaning can be distinguished: (1) metaphors comparing the principal's position to a game or adventure (1a, $1 \mathrm{~b})$ and (2) metaphors associating the position with positive feelings such as optimism and happiness (2a and $2 b$ ). 


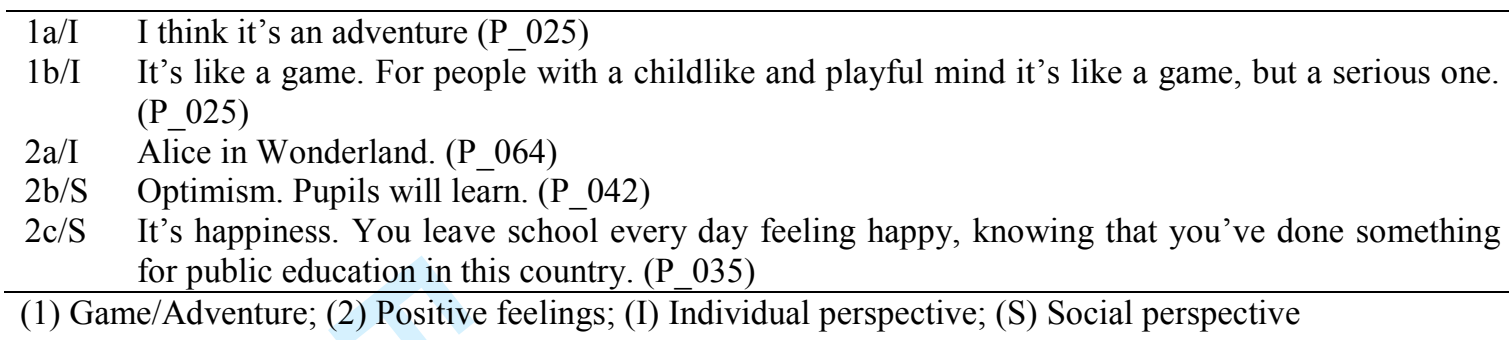
for public education in this country. (P_035)

(1) Game/Adventure; (2) Positive feelings; (I) Individual perspective; (S) Social perspective

The frequencies of code 2.2, which is related to satisfaction with work, are low. However, those who said they were satisfied with their role did so convincingly. Satisfaction was not only related to individual experiences $(\mathrm{F}(\%)=6.2)$, but also to social ones $(\mathrm{AF}(\%)=4.2)$. Narratives such as examples $2 \mathrm{~b}$ and $2 \mathrm{c}$ emphasise this.

\subsection{Rational view and motivational view. What type of motivation predominates in each leadership} model?

In order to identify the type of motivation that characterises each leadership model, a crossover study has been made of the codes for the two categories involved.

Table 8. Type of motivation according to leadership model. A crossover study of rational and motivational views

\begin{tabular}{lccc}
\hline \multicolumn{1}{c}{ Codes } & $\begin{array}{c}\text { 2.1 Duty } \\
\text { motivation } \\
\text { F (\%) }\end{array}$ & $\begin{array}{c}\text { 2.2 Hedonism } \\
\text { motivation } \\
\text { F (\%) }\end{array}$ & $\begin{array}{c}\text { Total } \\
\text { F (\%) }\end{array}$ \\
\hline 1.1 Guiding model & 58 & 10 & 68 \\
1.2 Paternalistic model & 22 & 2 & 24 \\
1.3 Directive model & 8 & 0 & 8 \\
\hline Total F (\%) & 88 & 12 & 100 \\
\hline
\end{tabular}


Table 8 shows that motivation for duty is the highest in each leadership model. Next, regardless of whether the principals and their metaphors indicate that their leadership is based on a guiding, paternalistic or directive model, it appears that their actions are governed by pressure to take on the duty and responsibility characteristic of the leadership function. Indeed, in their metaphors they constantly make use of the verbs must and have to. For example: "And of course the leader always has to lead the way, nobody else can do it, so they're the team leader and head worker at the same time". (P_001).

As regards motivation based on pleasure, it can be seen that there is no metaphor representative of the directive model associated with this. As for the guiding and paternalistic models, the metaphors that identify this type of motivation are a minority. They include expressions identified not with duty but with personal satisfaction, such as believe, value, coordinate, etc. For example: "The leadership function is believing in what you think and what you do above everything else”. (P_047)

\subsection{The key terms that enable us to associate emotions with the leadership view}

Since the metaphors from the first category, the rational view, make it possible to analyse certain emotions that are implicit though not as intense as in the second, this section will concentrate on highlighting their positive or negative character, recognising the terms that enable us to place them at one extreme or the other (positive feelings and negative feelings).

In Figure 1 it can be seen that principalship, from both rational and motivational view, is experienced more negatively than positively $(F(\%)=73$ vs. 27). Naturally the contributions 
collected under the duty motivation show that the difficulties are experienced most of all on an individual level. In this case the metaphors include terms indicative of seeing principalship as a burden, such as frustration, knocks, loneliness, imbalance, uncertainty, inability and sacrifice.

\section{[insert Figure 1]}

Figure 1. Frequency percentages for the character of the emotions associated with the leadership view

The positive emotions associated with the hedonism motivation are rather more balanced as regards individual or social perspective $(\mathrm{F}(\%)=6.2$ vs. 4.2$)$. The individual perspective has a predominance of positive emotions. The terms that enable us to clearly recognise the implicit experience of positive emotions include exciting, inherent motivation, fun, nice, utopia, love, optimism, happy, etc.

Although it is easear to recognize the emotions in the second category because they are explicit, those in the first category - despite being less intense and explicit - can also be identified. In this case, Figure 1 shows that the guiding model generates more negative than positive emotions ( $\mathrm{F}(\%)$ $=22.9$ vs. 12.5). However, the negative emotions are associated with an individual guide model, while the positive emotions are associated with a social guide model. The difficulty is expressed in the physical and mental exhaustion involved in "opening up the way for everyone else", while the satisfaction comes precisely from recognition of the responsibility the principal has. The terms that reflect the experience of negative emotions in this model would include tiredness, uncertainty, erosion, rough waters, stumbling blocks, waves to dodge, etc. The terms used as metaphors in the 
social guide model, on the other hand, would include ease, help, relief, recognition, trust, energy, etc.

In the case of the paternalistic model, negative emotions continue to predominate $(\mathrm{F}(\%)=8.3$ vs. 4.2). These are especially identified with the social paternalistic model. Having to look out for the welfare of others means that in the metaphors we see terms like attacks, defence, protection, make sure everything works out, take charge of, give warmth, look after, etc.

Finally, it can be seen that the directive leadership model, which has a definite individual character, also generates negative emotions. The principal experiences feelings of overload and responsibility which manifest themselves through the use of terms such as authority, responsibility, change of direction, unilateral decision-making, etc.

\section{Discussion}

This section seeks to answer the questions posed by the research as regards how principals in Spain see the figure of the principal and how they feel about it.

\subsection{The prevalence of the guiding leadership model and the duty motivation}

The metaphorical approach which referred to principals as guides was significant. This view could be seen as similar to the transformational or distributed models, as established in Bush and Glover's (2014) classification, depending on the individual or social perspective expressed in the metaphor. From the transformational point of view, principals implement change in an institution by sharing their own vision with others. Some of the metaphors referring to this would be those of the 
orchestra conductor, the captain of a ship, and the first carriage of a train. Rather than giving orders, the principal attempts to influence and guide the members of the organisation in order to achieve the objectives set by the Administration (Bass and Riggio, 2006). Other guiding metaphors, although a minority, were better aligned with the distributed leadership model because they implied a shared vision, as in the case of the human assembly lines, the cogs and the human body.

The often-stressed role of guide could be related to instructional leadership when used to create a good teaching environment in which teachers receive support and have the opportunity to contribute to the school curriculum (Wahlstrom et al., 2010). Some examples of such metaphors would be coach and chef.

Participants' metaphors alluding to a paternalistic model sometimes referred to their role being more of a servant leadership (Greenleaf, 1977). They seek to guarantee the growth and well-being of the members of their community. They put the needs of the community before their own and aim to encourage, first and foremost, the personal and professional needs of teachers. This could be related to the authentic leadership referred to by Bush and Glover (2014). The metaphors used by the principals referred to the protection of followers by the leader, and they are of a more intimate, sentimental, friendly and idyllic nature. For example, they see the principal as a medieval knight, a smiling presence and a parent.

Finally, it is important to highlight the very low percentage of frequencies referring to the principals' directive or authoritarian role. Here the most direct relationship with the models established by Bush and Glover (2014) would be leadership as a managerial role. This is formal 
leadership, dependent on the organisation and coercive in nature. Furthermore, it evokes transactional leadership, giving excessive importance to the power, expertise and authority of leaders. The metaphors used by participants rarely referred to adopting an autocratic role; when they did, it was mainly for decision-making purposes, when they were faced with conflicts that required a rapid solution, or in emergencies. This indicates that leaders valued participation, collaboration and the shared commitment of the members of the community.

As far as the motivational view is concerned, there is a clear predominance of the duty motivation. This dual view of motivation is also put forward in a similar way in Gebauer et al. (2008), but to assess the prosocial motivation that may be driven by the pleasure involved in helping or the pressure we feel to do so. In this case in particular, the data indicate that principals lead not because they find in principalship an opportunity to grow and for personal satisfaction, which could be related to professional well-being and security, an area to explore in future studies, but mainly because they understand it as a responsibility and a duty they have to take on. This type of motivation predominates in all three leadership models in the study.

\subsection{Principals' feelings about their leadership development}

Principals' perceptions and feelings could help them reflect on their dilemmas and problems and are an opportunity for enhancing knowledge on the subject (Alvesson and Spicer, 2010). In this case the emotional charge in the motivational view of their metaphors is more than evident. In general, they stressed the difficulties of the job more than its rewarding aspects, which points to a prevalence of negative emotions. Their metaphors referred to being overwhelmed by responsibility, to a lack of 
autonomy, little recognition, a huge workload and the variety of tasks they have to perform, etc. For example, they referred to the boulder of Sisyphus, a long-distance runner, a highly-qualified caretaker or a bad dream. These feelings are consistent with studies in which the difficulties of the directive role were identified (Tucker, 2010). These negative feelings are also particularly associated with the three leadership models identified in the most rational view. It appears that the directive model generates feelings of responsibility and weight from a personal perspective. The paternalistic model also gives rise to negative feelings, especially from the social perspective. This could possibly be explained by how responsible principals feel for the welfare of all the other members of the community and the efforts they have to make in this respect. Finally, although the negative and positive emotions are more balanced in the guiding model, the former are associated with an individual guide model, which is predominant.

It is encouraging that some metaphors, although fewer than half of those collected, described the role as an adventure, a challenge. They also referred to the position of principal as being highly valued, and to the positive repercussions of their work on pupils, which generates positive emotions. These perceptions show how leaders can have a positive effect on learning, on professional teaching development and on the building of a school culture, if their professional learning becomes a joint endeavour (Day et al., 2011; May and Supovitz, 2011).

\subsection{Individual and shared leadership models}

The analysis of the individual and social perspective of the metaphors leads us to say that, while the contributions indicate that leaders valued the community, the roles they stressed continue to reflect 
models with an individual and hierarchical perspective. While the models are not authoritarian, leaders and followers were clearly identified. The formal leader of the institution was the main source of power. The participants' conception of their role is very different from current leadership trends, which direct the focus of attention from individuality and hierarchy towards a shared social vision (Crawford, 2012; Harris, 2013). Although many metaphors with a social perspective have been formulated, especially from the rational view - possibly influenced by the theoretical-practical culture and the emphasis it places on this factor, given that discourses shape and are shaped by how members of a culture see and act towards a given phenomenon (Alvesson and Spicer, 2010) - this shift from the individual to the shared cannot be seen in their discourses. Thus it has not been possible to establish a real link between the metaphors and the shared leadership models highlighted by Bush and Glover (2014), since none of the participants alluded to shared perspectives in a very consistent way.

Finally, it is important to note that although in certain models the social perspective generates satisfaction, as in the case of guiding, when exercised from an individualist and unsharing stance it continues to generate emotions of responsibility, exhaustion and frustration, as can clearly be seen in the social paternalistic model. Although this is an area that needs to be studied in greater detail, it leads us to believe that perhaps the adoption of shared leadership models would generate positive emotions. The redistribution of tasks would immediately balance some of the feelings identified, such as loneliness, overload, responsibility, etc. 


\section{Conclusions}

The leadership models with which we have been able to associate the participants' metaphors reveal that no definite model appears in the regulations at national level. Although a slowly-growing argument in favour of more shared leadership models based on the functions established by the law has been gaining ground, in practice leadership continues to be locked into an individualist perspective. The tradition of centralisation and scant institutional autonomy give rise to unipersonal, authoritarian-type styles of leadership.

The regulatory confusion regarding the functions that principals have to take on, and therefore the model the Administration would like to see implemented, leads to inconsistencies between the implicit and explicit guidelines included in the regulations. Until these policies are brought into line with trends in leadership and signal a true commitment to shared leadership models, school management teams in Spain will be condemned to be led by principals who exercise a type of leadership that in most cases is experienced as a burden or, on the contrary, impose their own will in an attempt to develop their own leadership model, dodging administrative obstacles in the process.

On a policy level, efforts should also be made to develop new training programmes that are much more practical and contextualised. These would allow leaders to transform the perceptions they have of their own practices. In order to do this, a collaborative culture should be fostered to encourage the nurturing and development of learning communities (Aubusson et al., 2007), in which principals can reflect on their own conceptions of leadership. This recognition of their values, attributes and competences is directly related to the improvement of learning achievements. 
Consequently, it is of interest that principals should take part in rich and varied professional and learning situations, which would have an impact on the metaphors they build (Dubinsky et al., 2013).

A new research path would be to assess how principals' training can change their leadership model on both theoretical and practical levels. It would also be useful to go more deeply into the correlations between the principals' leadership models, their type of motivation and the feelings they experience. Evaluating what types of emotion are generated by different types of motivation in the leadership models could be a future line of research. Finally, we consider it a limitation of this study that, during the process of analysing the metaphors, we have paid little attention to factors such as gender, socioeconomic context and school culture. These should also be explored in greater detail to enable us to arrive at more new conclusions regarding leadership models in school principals, their motivation to act and the feelings to which they give rise.

\section{References}

Akar H and Yildirim A (2011) Change in teacher candidates' metaphorical images about classroom management in a social constructivist learning environment. Teaching in Higher Education 14(4): 401415. DOI: $10.1080 / 13562510903050152$

Alvesson M and Spicer A (2010). Metaphors we lead by: Understanding leadership in the real world. UK: Routledge.

Argyropoulou E and Hatira K (2014) Metaphors and drawings as research tools of head teachers' perceptions on their management and leadership roles and responsibilities. European Early Childhood Education 
Ärlestig H, Day C and Johansson O (2016) International School Principal Research. In H Ärlestig, C Day and O Johansson (eds.) A Decade of Research on School Principalship. Switzerland: Springer, pp. 1-9. DOI: 10.1007/978-3-319-23027-6_1

Aubusson P, Steele F, Dinham S and Brady L (2007) Action learning in teacher learning community formation: informative or transformative? Teacher Development 11(2): 133-148. DOI: $10.1080 / 13664530701414746$

Avidov O (2016) Understanding teachers' attitude toward educational reforms through metaphors. International Journal of Educational Research 77(2): 117-127. DOI: 10.1016/j.ijer.2016.03.008

DOI: http://dx.doi.org/10.1016/j.ijer.2016.03.008

Barsalou LW (1999) Perceptual symbol systems. Behavioral and Brain Sciences 22: 577-660.

Bass B and Bass R (2008) The Bass handbook of leadership. New York, NY: Free Press.

Bass B and Riggio R (2006) Transformational leadership. New York, NY: Jossey Bass.

Bolívar A and San Fabián JL (2013) La LOMCE, ¿una nueva ley para mejorar la calidad educativa? (The LOMCE Education Act: a new law for improving quality in education? Organización y Gestión Educativa (Educational Organization and Management) 1(1): 7-11.

Bruggencate G, Luyten H, Scheerens J and Sleegers P (2012) Modeling the influence of school leader son student achievement: How can school leaders make a difference? Educational Administration Quarterly 48(1): 699-732. DOI: 10.1177/0013161X11436272

Bush T (2011). Succession planning in England: New leaders and new forms of leadership. School. Leadership \& Management 31(3): 181-198. DOI: 10.1080/13632434.2010.545383 
Bush T and Glover D (2014) School leadership models: What do we know? School Leadership \& Management 34(5): 553-571. DOI: 10.1080/13632434.2014.928680

Cho JY and Lee E (2014) Reducing confusion about grounded theory and qualitative content analysis: Similarities and differences. The Qualitative Report 19(32): 1-20.

Cole FL (1988) Content analysis: process and application. Clinical Nurse Specialist 2(1): 53-57.

Crawford M (2012) Solo and distributed leadership: Definitions and dilemmas. Educational Management Administration \& Leadership 40(5): 610-620. DOI: 10.1177/1741143212451175

Davis S, Darling-Hammond L, LaPointe M and Meyerson D (2005) Review of research, school leadership study: Developing successful principals. Palo Alto, CA: Standford Educational Leadership Institute.

Day C, Gu Q and Sammons P (2016) The impact of leadership on student outcomes: How successful school leaders use transformational and instructional strategies to make a difference. Educational Administration Quarterly 52(2): 221-258. DOI: 10.1177/0013161X15616863

Day C, Sammons P, Hopkins D, Harris A, Leithwood K, Gu, ... Kington A (2009) The impact of school leadership on pupil outcomes. Nottingham, UK: National College of School Leadership.

Day C, Sammons P, Leithwood K, Hopkins D, Gu Q, Brown E and Ahtaridou E (2011). Succesful school leadership. Linking with learning and achievement. London, UK: McGraw-Hill.

Dubinsky JM, Roehrig G and Varma S (2013) Infusing neuroscience into teacher professional development. Educational Researcher 43(6): 317-329. DOI: 10.3102/0013189X13499403

Elo S and Kyngäs H (2007) The qualitative content analysis process. Journal of Advanced Nursing 62(1): 107-115. Flores MA and Day C (2006) Contexts which shape and reshape new teachers' identities: A 
multi-perspective study. Teaching and Teacher Education 22(2): 219-232. DOI: $10.1016 /$ j.tate 2005.09 .002

Frost, D. (2008). Teachers Leadership: values and voice. School Leadership and Management 28(4): $337-352$.

General Act of Parliament (2013). Ley Orgánica 8/2013, de 10 de diciembre, para la mejora de la calidad educative (General Law 8/2013 of 9 December on Improving Quality in Education). Boletín Oficial del Estado (Official State Bulletin), 10/12/2013.

Glaser B and Strauss A (1967) The discovery of grounded theory: Strategies for qualitative research. London: Weidenfeld \& Nicholson.

Greenleaf K (1977) Servant leadership. Mahwah, NJ: Paulists Press.

Gu Q and Johansson O (2013) Sustaining school performance: School contexts matter. International Journal of Leadership in Education 16(1): 301-326. DOI: 10.1177/1365480210376487

Hancock R, Hary Ch and Müller U (2012) An investigation of factors impacting the motivation of German and US teachers to become school principals. Research in Comparative and International Education 7(3): 352-363. DOI: $10.2304 /$ rcie.2012.7.3.352

Harris A (2013) Distributed leadership Friend or Foe? Educational Management Administration \& Leadership 41(5): 545-554. DOI: 10.1177/1741143213497635

Hsieh HF and Shannon S (2005) Three approaches to qualitative content analysis. Qualitative Health Research 15: 1277-1288.

Hopkins D and Higham R (2007) System leadership: mapping the landscape. School Leadership \& Management 27(2): 147-166. DOI: 10.1080/13632430701237289 
Huber J, Caine V, Huber M and Steeves P (2013) Narrative inquiry as pedagogy in education. The extraordinary potential of living, telling, retelling, and reliving stories of experience. Review of Research in Education 37(1): 121-242. DOI: 10.3102/0091732X12458885

Huber GL and Gürtler L (2013) AQUAD 7. Manual: The analysis of qualitative data. Tübingen, Germany: Authors. Available at: http://www.aquad.de/materials/manual_aquad7/manual-e.pdf (accessed 20 July 2015).

Gebauer JE, Riketta M, Broemer P and Maio GR (2008). Pleasure and pressure based prosocial motivation: Divergent relations to subjective well-being. Journal of Research in Personality 42: 399-420. DOI: 10.1016/j.jrp.2007.07.002

Katzenmeyer M and Moller G (2009) Awakening the sleeping giant: Helping teachers develop as leaders. Thousand Oaks, CA: Corwin Press.

Lakoff G and Johnson M (1980) Metaphors we live by. Chicago, US: University of Chicago Press.

Lambert L, Walker D, Zimmerman D, Cooper J, Dale M, Gardner M and Szabo M (2002) The constructivist leaders. New York, NY: Teachers College Press.

Lee S and Schwarz N (2012). Bidirectionality, mediation, and moderation of metaphorical effects: The embodiment of social suspicion and fishy smells. Journal of Personality and Social Psychology 20: 1-13. DOI: $10.1037 / \mathrm{a} 0029708$

Liljengerg M (2015) Distributing leadership to establish developing and learning school organizations in the Swedish context. Educational Management Administration \& Leadership 43(1): 152-170. DOI: $10.1177 / 1741143213513187$

Lincoln YS and Guba EG (1985) Naturalistic Inquiry. London: Sage. 
Mahlios M, Shaw DM and Barry A (2010) Making sense of teaching through metaphors: A review across three studies. Teachers and Teaching: Theory and Practice 16(1): 49-71. DOI: $10.1080 / 1354060090347564$

May H and Supovitz J (2011) The scope of principal efforts to improve instruction. Educational Administration Quarterly 47(2): 332-352. DOI: 10.1177/0013161X10383411

Morgan G (1986). Images of organization. Beverly Hills: Sage.

Patchen T and Crawford T (2011) From gardeners to tour guides: the epistemological struggle revealed in teacher-generated metaphors of teaching. Journal of Teacher Education 62(3): 286-298. DOI: $10.1177 / 0022487110396716$

Pinnegar S, Mangelson J, Reed M and Shaina G (2011) Exploring pre-service teachers’ metaphors plotlines. Teaching and Teacher Education 27(3): 639-647. DOI: 10.1016/j.tate.2010.11.002

Robinson VMJ, Hohepa M and Lloyd C (2009) School leadership and student outcomes: Identifying what works and why. Best evidence synthesis iteration. Wellington, NZ: Ministry of Education.

Robinson VMJ, Lloyd CA and Rowe KJ (2008) The impact of leadership on student outcomes: An analysis of the differential effects of leadership types. Educational Administration Quarterly 44(5): 635-674. DOI: 10.1177/0013161X08321509

Saban A (2010) Prospective teachers' metaphorical conceptualizations of learner. Teaching and Teacher Education 26(2): 290-305. DOI: 10.1016/j.tate.2009.03.017

Saban A, Kocbeker BN and Saban A (2007) Prospective teachers conceptions of teaching and learning revealed through metaphor analysis. Learning and Instruction 17: 123-139. DOI: 10.1016/j.learninstruc.2007.01.003 
Seiler G (2013) New metaphors about culture: implications for research in science teacher preparation. Journal of Research in Science Teaching 50(1): 104-121. DOI: 10.1002/tea.21067

Slepian ML and Ambady N (2014). Simulating sensorimotor metaphors: Novel metaphors influence embodied cognition. Cognition 130(3): 309-314. DOI: 10.1016/j.cognition.2013.11.006

Starratt R (2004) Ethical leadership. San Francisco, CA: Jossey Bass.

Thomas L and Beauchamp C (2011) Understanding new teachers' professional identities through metaphor. Teaching and Teacher Education 27(4): 762-769. DOI: 10.1016/j.tate.2010.12.007

Tucker S (2010) An investigation of the stresses, pressures, and challenges faced by primary school principals in context of organizational change in schools. Journal of Social Work Practice 24(1): 63-74. DOI: $10.1080 / 02650530903532757$

Wahlstrom K, Louis K, Leithwood K and Anderson S (2010) Investigating the links to improved student learning. New York, NY: The Wallace Foundation.

Zhao H, Coombs S and Zhou X (2010) Developing professional knowledge about teachers through metaphor research: Facilitating a process of change. Teacher Development 14(3): 381-395. DOI: $10.1080 / 13664530.2010 .504024$ 


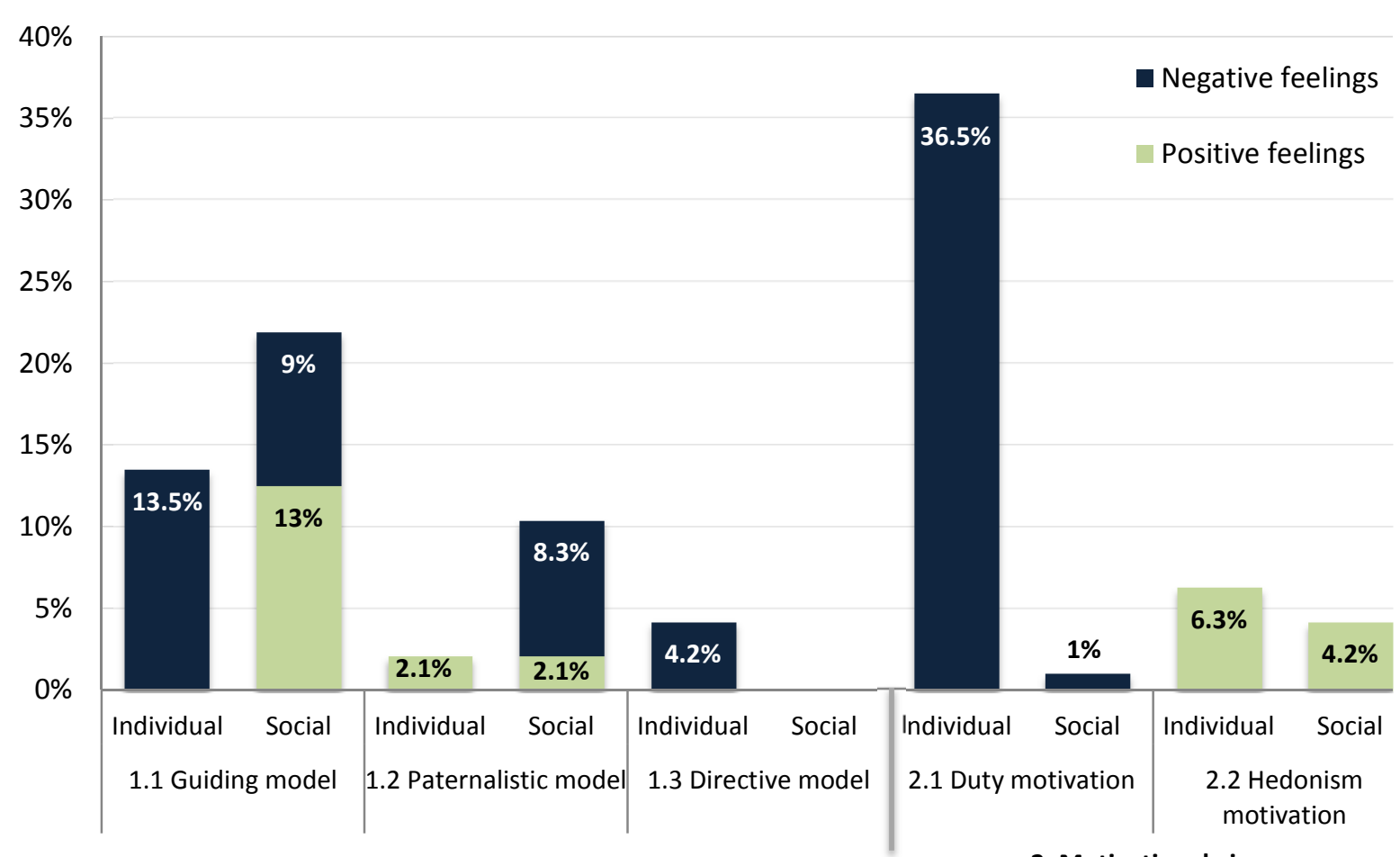

1. Rational view

2. Motivational view 


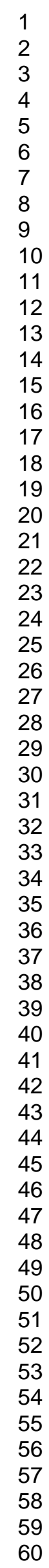




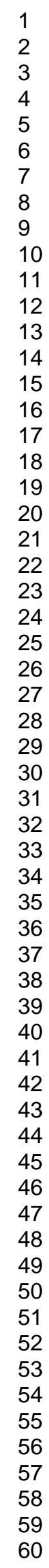

37 